\title{
DEGRADATION OF THE MAIN GAS PIPELINE MATERIAL AND MECHANISMS OF ITS FRACTURE
}

\author{
Pavlo MARUSCHAK ${ }^{\mathrm{a}}$, Iryna DANYLIUK ${ }^{\mathrm{a}}$, Olegas PRENTKOVSKIS ${ }^{\mathrm{b}}$, Roman BISHCHAK $^{\mathrm{c}}$, \\ Andriy PYLYPENKO ${ }^{d}$, Andriy SOROCHAK ${ }^{\mathrm{a}}$ \\ ${ }^{a}$ Department of Industrial Automation, Ternopil National Ivan Pul'uj Technical University, \\ Rus'ka str. 56, 46001 Ternopil, Ukraine \\ ${ }^{b}$ Department of Transport Technological Equipment, Vilnius Gediminas Technical University, \\ Plytinès g. 27, LT-10105 Vilnius, Lithuania \\ ${ }^{c}$ Department of Welding of Main Pipelines, Ivano-Frankivsk National Technical University of Oil and Gas, \\ Karpatska str. 15, 76000 Ivano-Frankivsk, Ukraine \\ ${ }^{d}$ Department of Strength of Materials, National University of Life and Environmental Sciences of Ukraine, \\ Heroyiv Oborony str. 15, 03041 Kyiv, Ukraine
}

Received 18 Mar 2014; accepted 04 Sep 2014

\begin{abstract}
The effect of the in-service scattered damage in the pipe wall metal is evaluated, and the effect of hydrogen absorbed by metal on the variation of the structure and mechanical properties of the main gas pipeline after a long-term operation is found. The main regularities in the graded nature of the static deformation process and the effect of hydrogenation on the scattered damage and fracture accumulation are found.
\end{abstract}

Keywords: fracture, failure, structural damage, strain localisation, hydrogenation, degradation, gas pipeline.

\section{Introduction}

About a half of the main pipelines of Ukraine have been in service for more than 20 years, and about a quarter of them - for more than 30 years (Nykyforchyn et al. 2010; Maruschak et al. 2013a). Stringent requirements placed on the integrity and efficiency of operation of such technical systems call for an increased accuracy of evaluation of their characteristics after a long time of operation (Hood 1974).

It is known that the structure determines the mechanical properties of materials of the pipeline systems (Liang et al. 2009). Grain size variation, accumulation of structural damage on their boundaries, accumulation of hydrogen in the vicinity of inclusions change the material characteristics and its resistance to the static and dynamic loadings (Kryzhanivs'kyi, Nykyforchyn 2011; Azevedo, Sinatora 2004). That's why it is important to establish the main regularities in the structural degradation of the material and variation of the physical and mechanical properties.

Special attention should be paid to hydrogenation, since hydrogen facilitates the propagation of damage, in particular, the nucleation and growth of microcracks (Lublińska et al. 2007). It is known that the content of the residual hydrogen in the service-exposed pipeline metal is higher than that in the initial material (Nykyforchyn et al. 2010). In a number of works it is proved, based on the evaluation of the hydrogen permeability of steels and hydrogen desorption kinetics, that cyclic loading increases the intensity of hydrogen trapping and the energy of its fixation in traps, which preconditions a higher defectiveness of the service-exposed metal (Nykyforchyn et al. 2010; Kryzhanivs'kyi, Nykyforchyn 2011).

Moreover, some works are known, in which the ambiguous effect of structural defects on the deformation properties of materials of gas and oil pipelines was found. In a number of cases, an increase in plasticity was observed due to the opening of multiple defects oriented perpendicular to the material load lines (Nykyforchyn et al. 2010; Kryzhanivs'kyi, Nykyforchyn 2011). The interest in such phenomena is caused by a specific character of the material structure after a long-term operation, when the material anisotropy manifests itself very clearly in the longitudinal and transverse directions (Nykyforchyn et al. 2009; Maruschak et al. 2012).

It is in such material that irreversible changes take place due to an increased specific share of grain boundaries, which causes variation of the deformation properties at the micro-, meso- and macrolevels (Panin, Egorushkin 2011; Makarov 2010). That is why the structure and properties of the service-exposed material differ significantly from those of the material in the initial state.

The purpose of this work is to perform a complex analysis of the structural and mechanical damage of the main pipeline after a long-term operation, and the decreased strength and deformation properties of the material. 


\section{Research technique}

A section of the main gas pipeline "Kyiv - West of Ukraine-1" (KWU-1) was investigated after 40 years of operation under ground. The gas pipeline has a diameter of $1020 \mathrm{~mm}$, wall thickness of $10 \mathrm{~mm}$, and a rubberbituminous insulation. The failure of insulation caused formation of the corrosive damage on the external surface of pipes in the form of spots, pits and cavities of different size and depth due to the interaction between the pipe metal and the medium. Lack of insulation on the analyzed section of the main gas pipeline KWU-1 from steel $17 \mathrm{G} 1 \mathrm{~S}$ according to TU 1-150-67 caused the formation of multiple corrosive damage on the external surface. A fragment was cut from the pipe during repair (Fig. 1), in order to evaluate the metal damage.

The kinetics of the scattered damage accumulation in the service-exposed material under static loading was described by the complete diagrams method, where $\varepsilon_{p}$ is the material loosening strain; the current value of the lateral strain coefficient is taken as the main parameter (Lebedev et al. 2002, 1996).

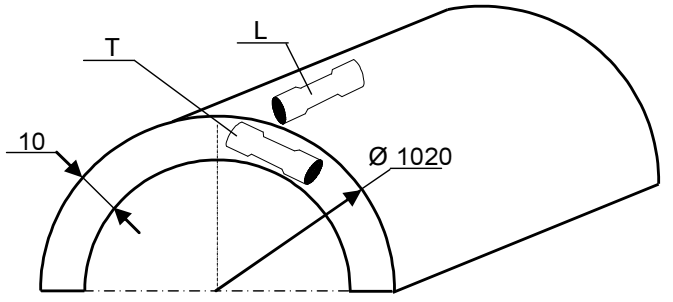

Fig. 1. Scheme of the investigated fragment of the serviceexposed pipeline KWU-1 1996):

The material loosening strain (Lebedev et al. 2002,

$$
\varepsilon_{p}=(1-2 \cdot \mu(\varepsilon)) \cdot \varepsilon,
$$

where: $\mu(\varepsilon)$ is the current value of the lateral strain coefficient.

The metallographic templates cut from the pipe with the diameter of $\mathrm{mm}$ in the radial and axial directions from the internal and external surfaces of the pipe were investigated. Cutting was performed on the Q-80Z (URMO$80 \mathrm{~A})$ special purpose machine with water cooling. The surface analysed was polished on the MR-1V facegrinding machine and treated in $2 \%$ nitric acid solution, the templates were investigated on the MMO-1600AT metallographic microscope.

\section{Corrosive defects}

It is known that pipeline systems, which have been under ground for more than 5 years, usually contain corrosive and metallurgical microdefects or microcracks (Lublińska et al. 2007). The effect of technological loads and residual stresses combined with the medium (soil), which has a certain humidity and acidity, intensifies the accumulation of damage and hastens the propagation of these defects (Ghajar et al. 2013). Figure 2 shows the distribution of pitting and corrosive pits on the surface of the main gas pipeline.

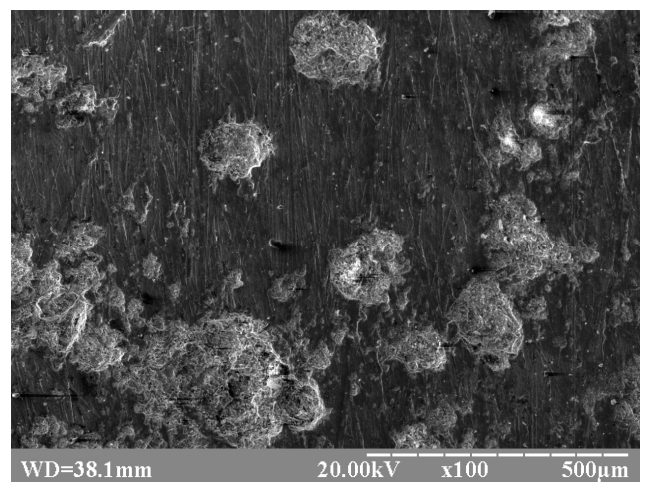

a)

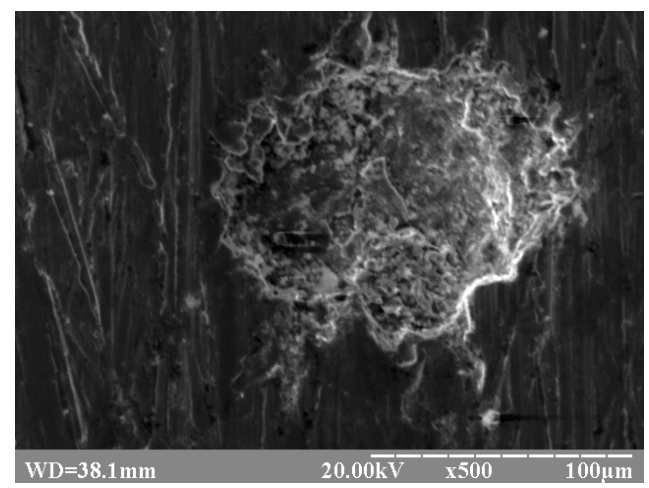

b)

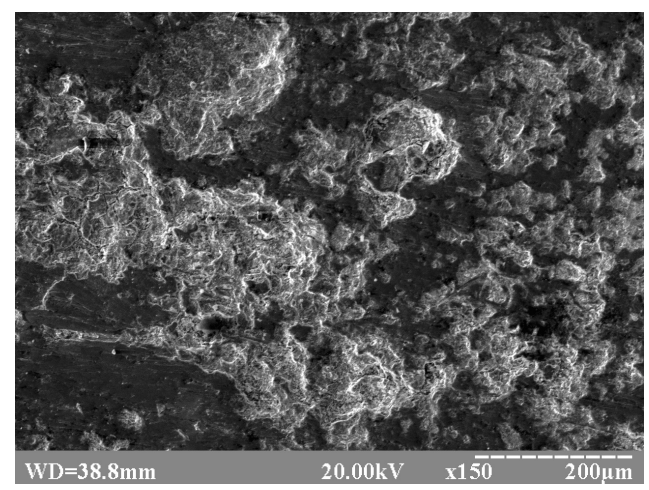

c)

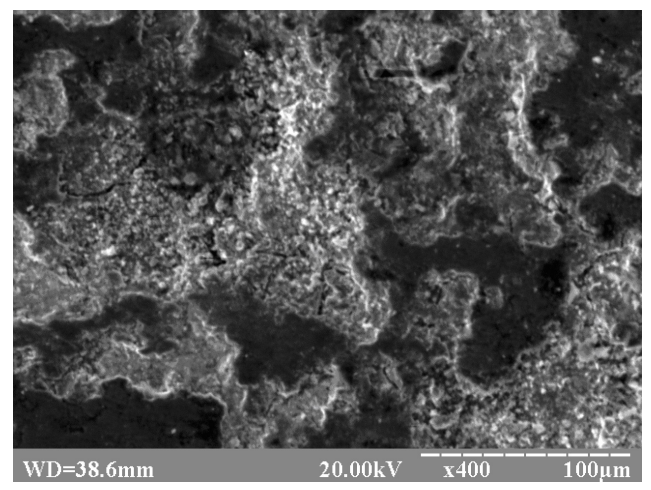

d)

Fig. 2. Pitting $(a, b)$ and corrosive pits $(c, d)$ found on the external surface of the gas pipeline after 40 years of operation 
In places of contact between the pipe metal and the corrosive medium, the acidification of the medium takes place under the insulation, which facilitates a reduction in the surface energy and hastens failure of the passivating film. The most active elements of the soil electrolytes are the halide chloride ion $\mathrm{Cl}^{-}$and the adsorbed hydrogen (Ghajar et al. 2013; Kotrechko et al. 2004).

As a result of microplastic deformation, the destabilization of the internal energetic state takes place on local sections of the pipe material, and the sensitivity to stress concentrators increases under the effect of hydrogen. Moreover, cyclic loading lowers the plasticity of the deformed metal, thus increasing its liability to the corrosive cracking under the effect of the hydrogenous medium (Nykyforchyn et al. 2010).

\section{Microstructure and properties of the pipe metal}

The templates cut in the axial direction are characterized by the clear-cut damage of the ferritic-pearlitic structure (Fig. 3a, b). A partial decarbonation of the pearlitic grains is detected on polished sections. Numerous defects in the form of laminations are found, which are oriented along the rolling direction and formed due to the hydrogenation of metal. These defects are called hydrogen lamination and hydrogen cracking (Nykyforchyn et al. 2010). Obviously, cracks nucleated on grain boundaries and propagated under the action of stresses by the "stresscorrosion" scheme (Lublińska et al. 2007). As is known, it is the localisation of the degradation processes between rolling fibers (Fig. 3c) that causes a significant reduction in the impact toughness of the service-exposed pipelines (Baron 2012).

In our opinion, the said defects testify to the overstrained condition of the analysed section (possibly, due to a local subsidence of soil), moreover, an increase in the internal stress caused the localisation of structural damage and its coalescence in the direction perpendicular to the maximum tensile stresses. A change in the density of metal damage is accompanied by a change in its geometry, size and spatial orientation, which preconditions a change in microhardness of the surface layers (Teirlinck et al. 1988). One of the main reasons for the appearance of the said defects is damage and loss of adhesive properties of the pipe coating, which caused the penetration of ground water into the pipe surface. Atomic hydrogen penetrated into the metal and accumulated in micropores and structural defects (Fig. 3b). In parallel, the decarbonation of metal developed due to blocking of carbon atoms by hydrogen atoms, thus decreasing the material plasticity (Kadkhodapour et al. 2011).

As a result of the performed investigations, the main regularities in the degradation processes that occur during a long-term operation were found:

- decreased mobility of dislocations due to an increased level of the internal microstrains of the material, which are the local traps for the accumulation of hydrogen;

- accumulation of structural defects and embrittlement due to hydrogenation;

- dispersed deformation defects and microcracks.

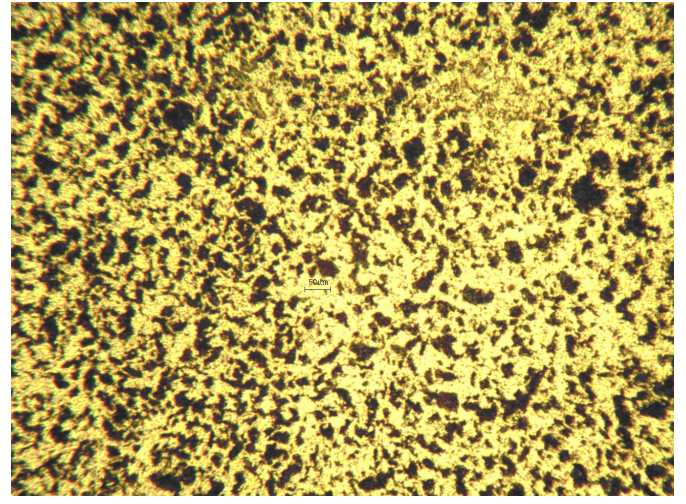

a)

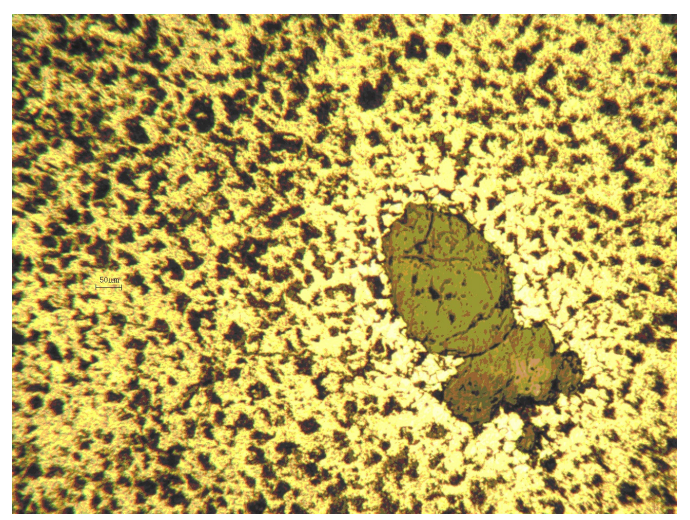

b)

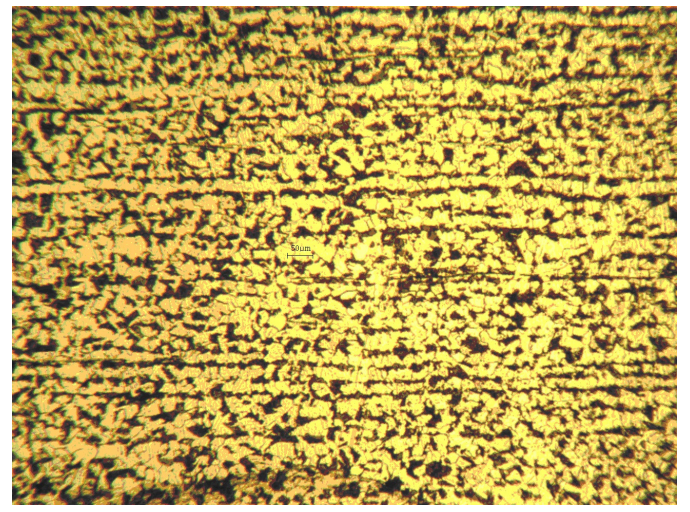

c)

Fig. 3. Microstructure of gas pipeline after 40 years of operation $(\times 200): \mathrm{a}-$ in the transverse direction, where a - external surface; $b$ - internal surface; $c-$ along the pipe axis

Complete stress-strain curves method is effective (Lebedev et al. 2002, 1996) in evaluating the effect of cutting direction on the damage accumulation kinetics and deformation properties of the material under static tensioning (Fig. 4a). It is found that the specimens cut in the longitudinal direction are characterized by a clearly seen yield plateau.

It is known that long-term operation causes changes in the kinetics of deformation defects accumulation in the structural material (Yasnii et al. 2012), and the level of the structural and mechanical damage of the material has an immediate effect on the regularities in the material failure (Fig. 4b, c). 


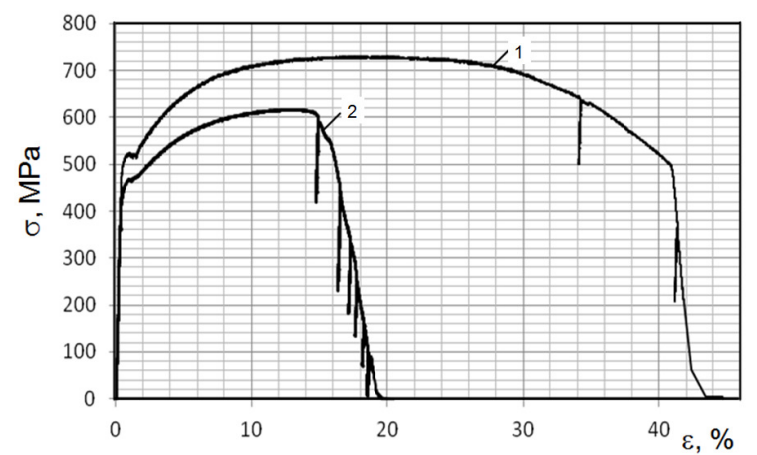

a)

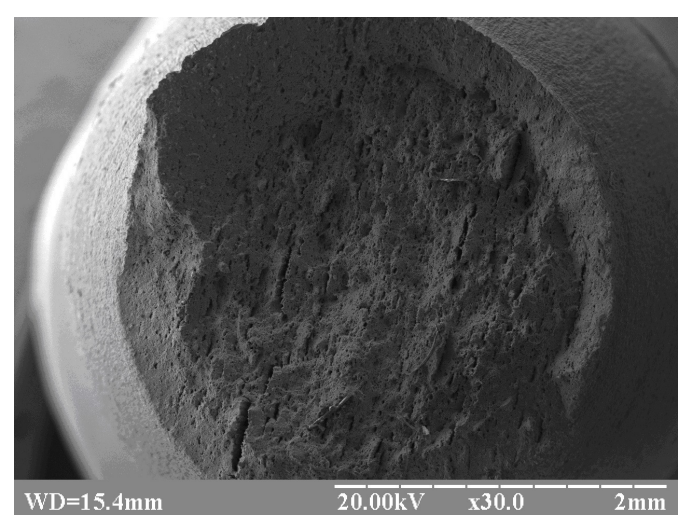

b)

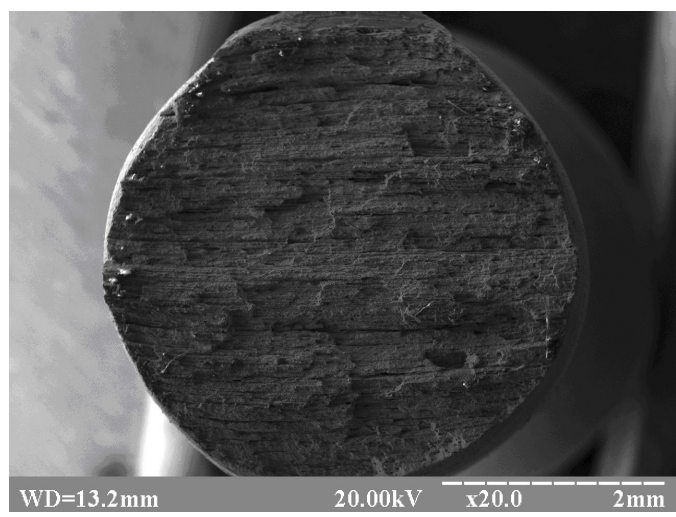

c)

Fig. 4. Complete static tension curves for the service-exposed 17G1S steel: a - cut in the longitudinal (1) and transverse (2) directions after 40 years of operation under ground; $b$ - microfracture of specimens cut in the longitudinal direction; $\mathrm{c}-\mathrm{mi}$ crofracture of specimens cut in the transverse direction

The presented data testifies to the fact that degradation, first of all hydrogenation, raises the degree of the material opening, due to which some essential differences between the deformation properties are observed (Fig. 5a). As is seen, in qualitative terms, the kinetics of the damage accumulation process in specimens with different degrees of deformation is similar to the insignificant strains, when deformation processes are localized in the vicinity of structural formations (macrolevel), in particular, a difference between the loosening strains of specimens at low strains $(\varepsilon=8 \%)$ was $2 \%$. However, at strains equal to $20 \%$, the difference between the loosening strains was $16 \%$.
For the specimens cut in the longitudinal direction with $\varepsilon=42 \%$, the loosening strain was $\varepsilon_{p}=27 \%$. For the specimens cut in the transverse direction the maximum relative strain was $\varepsilon=20 \%$, and the loosening strain was $\varepsilon_{p}=13 \%$.

So, the specimens cut in the longitudinal direction have better deformation properties (Fig. 5b). Lower strength and plasticity of the specimens cut in the transverse direction are connected with the processes of the preliminary hydrogenation and multiple lamination of the structure of the internal material layers (Fig. 5c). The said defects impede the involvement of the material mesovolumes in the plastic deformation process, which is confirmed by low values of the residual strain (Makarov 2000). Significant differences were also observed in the slopes of the descending branches of the stress-strain curves, which testify to a big difference between the mechanisms of macrofailure.

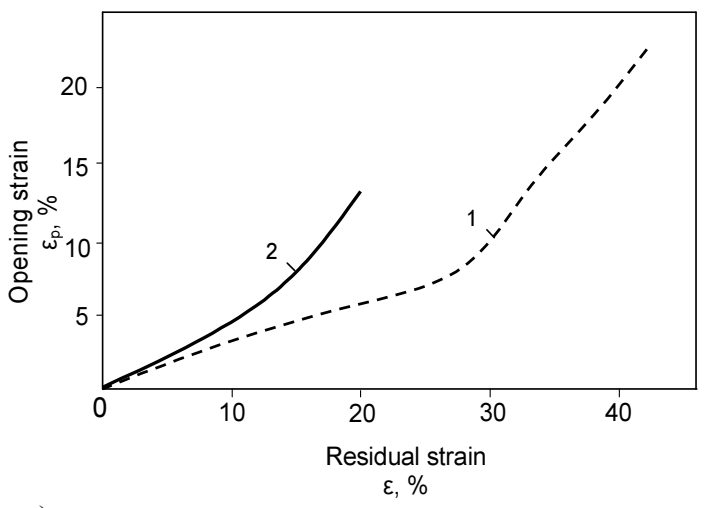

a)

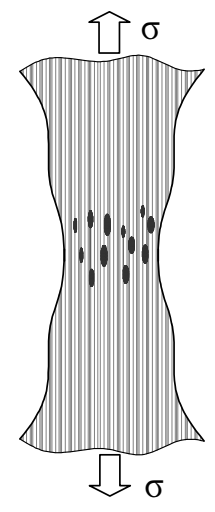

b)

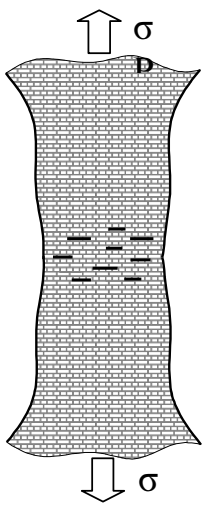

c)
Fig. 5. Visualization: a - dependence of loosening strains on the residual strain for the specimens of the longitudinal direction of cutting (1) and transverse direction of cutting (2); b - scheme of the deformation behavior of specimens cut in the longitudinal direction from the service-exposed pipe; c - scheme of the deformation behavior of specimens cut in the transverse direction from the service-exposed pipe

The macroanalysis of fracture surfaces of the specimens cut in different directions revealed a clear dependence of the material deformation properties on the crystallographic orientation. It is these parameters that account for 
the differences between the stress-strain curves for the steel cut from the pipe in various directions.

It is found that for the specimens of the longitudinal direction of cutting, the presence of the scattered damage causes intensification of the dimple separation. The fracture surface of the specimens cut from the service-exposed steel 17G1S is covered with a dense network of deep, largesized dimples combined with numerous laminations, which are connected with damage propagation during operation.

For the specimens of the transverse direction of cutting, the presence of the "composite" structure of the fracture surface in the form of micro- and macroprotrusions was recorded experimentally. Thus, when hydrogen affects the structure of the gas-pipeline metal, a great number of ordered structures are formed in the investigated material (material states), each of which has new mechanical properties (Balokhonov 2010).

It is found that the service-exposed steel is characterized by significant differences between the strength properties in various directions, however, they are higher than those in the initial material (see Table 1). Obviously, the exhaustion of plasticity of the gas pipeline material takes place during its operation. In addition, an increase in the relative elongation of the material cut along the pipe takes place, which is preconditioned by the opening of multiple defects in the damaged material (Nykyforchyn et al. 2010). The transverse direction of cutting, on the contrary, is characterized by a decreased relative elongation, which is caused by the material embrittlement and quasi-brittle shear mechanism of failure in the vicinity of structural defects.

Table 1. Mechanical properties of steel $17 \mathrm{G} 1 \mathrm{~S}$ of the main gas pipeline KWU-1 in initial state and after 40 years of operation

\begin{tabular}{l|c|c|c}
\hline \multicolumn{1}{c|}{ Properties } & $\begin{array}{c}\text { Yield } \\
\text { strength, } \\
\sigma_{y}[\mathrm{MPa}]\end{array}$ & $\begin{array}{c}\text { Tensile } \\
\text { strength, } \\
\sigma_{u l}[\mathrm{MPa}]\end{array}$ & $\begin{array}{c}\text { Elongation, } \\
\varepsilon[\%]\end{array}$ \\
\hline $\begin{array}{l}\text { Initial state of steel } \\
\text { (Certificate 162/3-69) }\end{array}$ & $420-435$ & $580-590$ & $23.5-26.0$ \\
\hline $\begin{array}{l}\text { Service-exposed steel } \\
\text { of the longitudinal } \\
\text { direction of cutting }\end{array}$ & 460 & 720 & 44.0 \\
\hline $\begin{array}{l}\text { Service-exposed steel } \\
\text { of the transverse } \\
\text { direction of cutting }\end{array}$ & 520 & 620 & 20.0 \\
\hline
\end{tabular}

\section{Mechanisms of deformation of the service-exposed material}

A difference in the mechanisms of deformation of specimens cut in the longitudinal and transverse directions also consists in:

\section{Microlevel:}

-in case of the longitudinal direction of cutting, the metallographic and fractographic analyses allowed revealing two micromechanisms of failure - the initial ductile (dimple) one in the central part of the specimen and subsequent shear one - in the peripheral part (Fig. 6a). Discontinuities (pores) are formed in places of accumulation of pearlite colo- nies. Deformation took place in the plastic manner and is connected with the processes of yielding of the material matrix, and the accompanying material opening processes on the whole;

- in case of the transverse direction of cutting, the analysis of fracture surfaces revealed a greater amount of secondary microcracks and laminations in the service-exposed steels as compared to the reserve pipe, moreover, there are signs of brittle fracture in the vicinity of laminations (Fig. 6d). Obviously, under conditions of the non-uniform stress state, all the non-uniformities have a significant effect on the multiplication and displacement of dislocations (since strains propagate not in the ideal monocrystalline material, but in the real one, their manifestations are distorted and localized on structural defects). Thus, the micrononuniformity of failure is connected with the processes of deformation of the hydrogen-embrittled material matrix and the accompanying processes of shear and separation of the material in the vicinity of defects (Makarov 2000). The physical investigations performed using the transmission electron microscopy allow presuming that deformation of such materials is connected with the formation of the ordered structures in the form of the volumetrically linked, localized "composite" formations at different scale levels.

\section{Mesolevel:}

-the longitudinal direction of cutting. With an increase in the specimen deformation level individual mesobands are hardened, and deformation continues in neighboring bands creating sections of the ordered mesorelief. With an increase of deformation, the intensity of failure of the initial banded fragmented mesosubstructure and the local softening of macrobands of the localized yielding increase (Fig. 6b). A symmetrical neck covered with mesobands of deformation is formed in the specimen. This facilitates redistribution of the linear and shear components of deformation. The plastic deformation bands are oriented in the direction of force application. Within the local stress concentration zones, some crack-like laminations with a well-developed curvilinear front are noticeable. The propagation of plastic shears from grain boundaries into the grain volume is accompanied by the appearance of the eddy motion in the elastically deformed material, which is necessary for the accommodation of strain in the neighboring areas (Makarov 2010). Individual grains, inclusion, etc., are involved in the accommodation shear and turns at the mesolevel as well as the whole fragments (grain conglomerates), which leads to the formation of the network of localized deformation bands (Maruschak et al. 2013b).

-the transverse direction of cutting. The view of the lateral specimen surface testifies to the brittle failure (Fig. 6d). At the same time, the presence of multiple cracks testifies to the partial relaxation of stresses during deformation. It is shown that due to the stress concentration in the vicinity of microcracks the first 
plastic shears are nucleated under mean stresses, which are much lower than the macroscopic yield point, and the sections of their localization are formed before the stress-strain curve enters the stage of strain hardening. These conclusions are confirmed by the calculations made for ceramics with various degrees of porosity investigated under compression conditions. In this case, the sources of local stress concentration are the boundaries between the pore and the base material (Makarov 2000).

Obviously, at this mesoscale level, deformation is incapable of relaxing the growing stresses - a transition of the deformation process to a higher scale level takes place. Immediately after its nucleation the crack propagated in the longitudinal direction within the area perpendicular to the direction of the maximum tensile stresses.

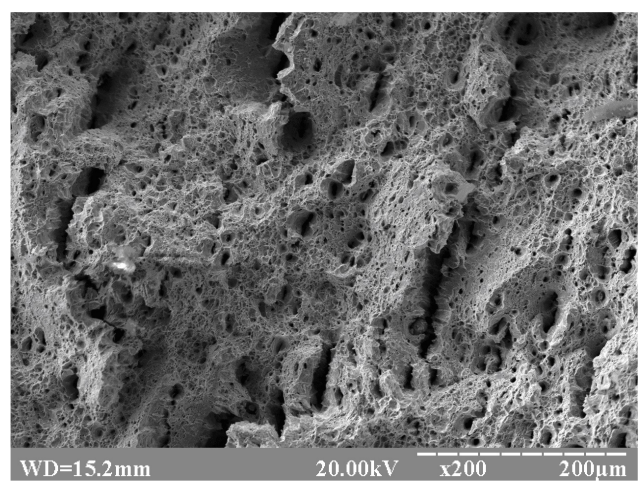

a)

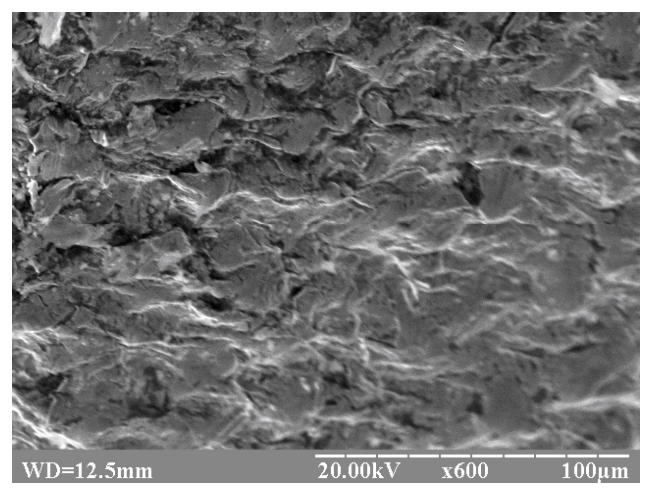

b)

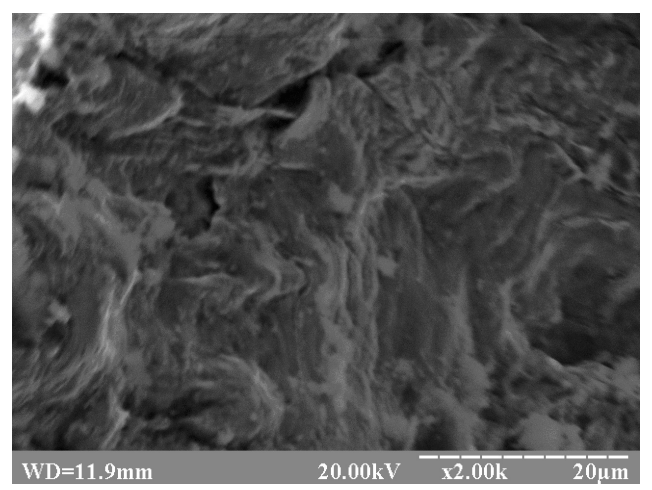

c)

\section{Macrolevel:}

-in case of the longitudinal direction of cutting, the service exposure causes an increase in the amount of stress concentrators. An increase in the macrostrain is accompanied by saturation of the material with micro- and mesodefects, moreover, the opening due to nucleation of defects is replaced by the opening due to increase in their sizes, coalescence of individual micropores and microcracks (Fig. 6d). Localization and concentration of pores in case of the increased strain are accompanied by their coalescence and the formation of an embryo macrocrack (Kachanov 1999);

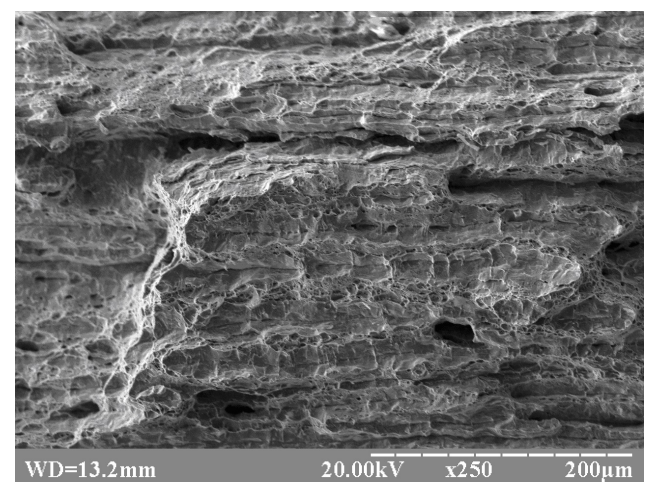

d)

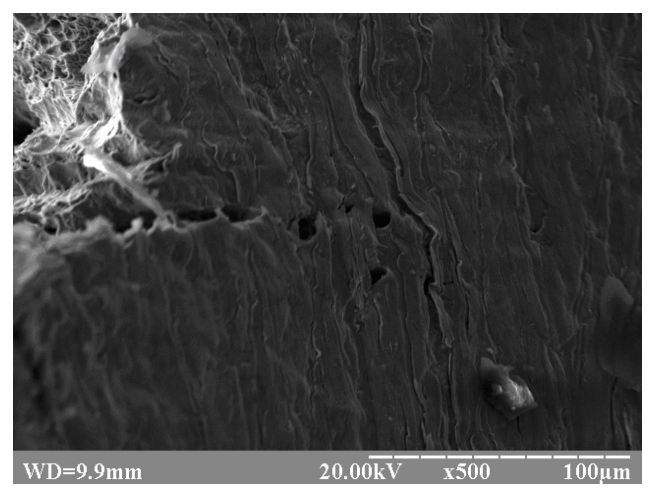

e)

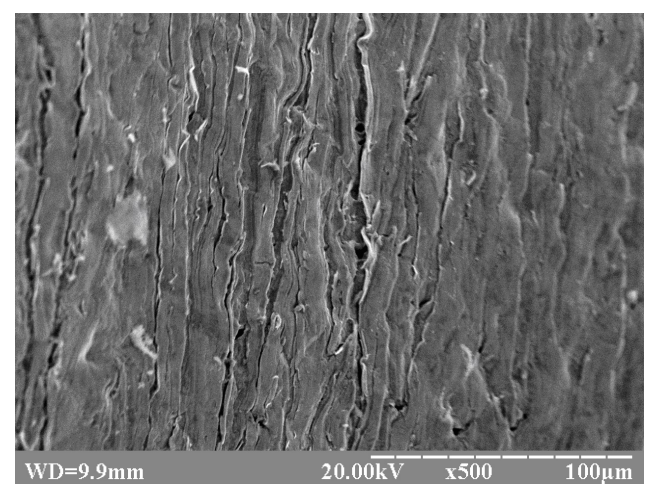

f)

Fig. 6. Fracture surfaces $-a, d$ and lateral surfaces $d, c, e, f$ of specimens from service-exposed steel 17G1S: (a) of the longitudinal $(\mathrm{a}-\mathrm{c})$ and transverse $(\mathrm{d}-\mathrm{f})$ direction of cutting after 40 years of operation 
-in case of the transverse direction of cutting, we observed a significant decrease in deformation properties of the steel, which gave grounds to believe that the reason for that was the developed defectiveness of the pipe wall metal (Fig. 6f). Very indicative in this case is the difference between deformation processes in the longitudinal and transverse directions, which depicts not only the low capacity of metal to deform plastically, but also an intensive coalescence (mainly by microspalling) of microcracks (Dominguez, Sevostianov 2011).

In this case, the mechanism of failure is determined by the ability of steel $17 \mathrm{G} 1 \mathrm{~S}$ to resist the shear stress and the separation stress. It should be noted that a change in the direction of cutting caused the appearance of additional failure mechanisms due to propagation of the macrocrack in two planes of the pipe (the axial and radial ones) (Cramer, Sevostianov 2009).

Attention should be paid to some peculiarities of deformation of steel $17 \mathrm{G} 1 \mathrm{~S}$, in particular, that yielding of the material cut in the transverse direction is much lower than that of the material cut in the longitudinal direction, which testifies to lack of a single mechanism of failure of the material during propagation of a crack.

The fracture work of the specimens cut in the radial direction is much lower than that of the specimens cut in the longitudinal direction. From the point of view of fracture mechanisms, the presence of the lateral shear mechanism was observed for such specimens, which is much less energy efficient than pure separation.

\section{Discussion}

It is known that several levels of deformation and failure can be distinguished in the quasi-static processes of deformation, which allow describing the synergetic instability of the process of deformation (Panin, Egorushkin 2011). If we consider the processes of deformation and failure of steel $17 \mathrm{G} 1 \mathrm{~S}$ taking into account the concept of structural levels, the graded nature of evolution in loss of the shear stability by materials should be pointed out. In addition, the microlevel is represented by grains and subgrains of the material, the mesolevel - by grain conglomerates, and the macrolevel considers the specimen as the quasiuniform medium (Yasniy et al. 2009).

In this case, the mesolevel is implemented by shear displacements of grain conglomerates, which cause the nucleation and coalescence of micropores, and a transition of the process of failure to the macrolevel. Moreover, the material structure has a significant effect on the development of the plastic deformation and failure processes in materials. In contrast to the elastic properties, which show low sensitivity to changes in the structure, the plastic and strength properties are highly sensitive to changes in the material structure (Yasniy et al. 2009).

So, the nonuniformity of materials is analyzed from two points of view. On the one hand - it is considered in the form of visible differences within the structure, and a difference between the mechanical properties, including the elasticity modules, yield points and other characteristics, which depict certain aspects of the mechanical be- havior of the material under loading. On the other hand it is analyzed indirectly by changes in the deformation behavior of the deformed solid body, which depicts the non-uniformity of the structural nonuniformity only in the averaged manner (integrally).

It should be made clear that the presence of hydrogen in the pipe wall of the operational gas pipeline may lead to the operational embrittlement even when its concentration does not exceed the maximum allowable value (Nykyforchyn et al. 2009).

This is connected with the fact that hydrogen, due to a high diffusion activity in metals, is redistributed within the structure of the pipe metal under the action of the elastic stress fields, which causes the formation of clusters in the most highly-stressed sections. As a result, the probability of the pore and crack formation increases.

According to the results of Maruschak et al. (2012), there are two main reasons that enhance the deformation properties of the material without its failure, and, correspondingly, its static strength. This is, first of all, the formation of the substructure with the well-developed boundaries capable of impeding propagation of a crack and a growth of disorientation of boundaries of the structural elements. The results obtained in this work allow for a quantitative evaluation of the effect of hydrogen on the mechanisms of deformation and failure of the gas pipeline steel after a long-term operation. A possibility of taking into account the effect of the mechanisms of deformation and pore formation on the regularities in failure of the pipe steel is shown in Table 2.

The peculiarities of morphology of the fracture surface of the main gas pipeline steel after a long-term operation (see Table 2) can be explained, taking into account the microstructural processes, which take place during

Table 2. Mechanisms of deformation and failure of serviceexposed steel 17G1S after 40 years of operation

\begin{tabular}{l|l|l}
\hline $\begin{array}{l}\text { Direction } \\
\text { of cutting }\end{array}$ & $\begin{array}{l}\text { Predominant mechanisms } \\
\text { of deformation }\end{array}$ & Failure mechanisms \\
\hline $\begin{array}{l}\text { Along the } \\
\text { pipe (L) }\end{array}$ & $\begin{array}{l}\text { Nonuniform microplastic } \\
\text { strains localized within } \\
\text { individual grains are pre- } \\
\text { conditioned by the struc- } \\
\text { tural damage and the } \\
\text { preliminary pore for- } \\
\text { mation in the initial struc- } \\
\text { ture. The accumulation } \\
\text { and coalescence of the } \\
\text { deformation defects lead } \\
\text { to variation of the degree } \\
\text { of compression of plastic } \\
\text { strains. }\end{array}$ & $\begin{array}{l}\text { Failure by the elastic- } \\
\text { plastic mechanism. } \\
\text { Some sections "en- } \\
\text { closed" with the elastic } \\
\text { boundaries are ob- } \\
\text { served. } \\
\text { Ductile separation of the } \\
\text { material within the } \\
\text { macroplane of the nor- } \\
\text { mal loading axis. At the } \\
\text { same time, relatively } \\
\text { small sections of shear } \\
\text { strains. }\end{array}$ \\
\hline $\begin{array}{l}\text { Across the } \\
\text { pipe (T) }\end{array}$ & $\begin{array}{l}\text { Extended sections of } \\
\text { elements of the internal } \\
\text { structure located between } \\
\text { defects are involved in } \\
\text { deformation. Significant } \\
\text { nonuniformity of defor- } \\
\text { mation of the "composite" } \\
\text { structure in the longitudi- } \\
\text { nal and transverse direc- } \\
\text { tions. }\end{array}$ & $\begin{array}{l}\text { Ductile-brittle mecha- } \\
\text { nism with quite a large } \\
\text { gradient of plastic strain } \\
\text { along the specimen } \\
\text { cross-section. The frac- } \\
\text { ture surface has a grad- } \\
\text { ed "composite" shape. } \\
\text { Failure by the } \\
\text { "shear+turn" mecha- } \\
\text { nism. }\end{array}$ \\
\hline
\end{tabular}


hydrogenation. As is known, one of the main processes is the accumulation of hydrogen in the material. The microstructural investigations show that the most typical areas of the intragranular accumulation of hydrogen are the surfaces of carbides and non-metallic inclusions, which is caused by the diffusion of hydrogen on the "carbidematrix" interface and the "inclusion-matrix" interface. In addition, the softening of the grain boundaries is developing fast, and the change of orientation of the polycrystal loading leads to an increase in the non-uniformity of deformation and significant differences between the deformation properties (Mishnaevsky et al. 2004).

\section{Conclusions}

The damage mechanisms of the pipe metal of the gas pipeline "Kyiv - West of Ukraine-1" (KWU-1) after 40 years of operation under ground are investigated, the main reasons for their appearance are found and analysed.

The regularities of the effect of the scattered damage on the processes of deformation at various scale levels are generalized using the approaches of physical mesomechanics. The process of deformation of the damaged material was analysed using the complete stress-strain curves, some sections of which correspond to the stages of the material failure.

The established regularities can be used for the evaluation of the main gas pipeline resistance to fatigue damage, as well as for the correct and rational choice of the permissible stress value, taking into account surface concentrators, and for prediction of the residual life of the structure.

\section{References}

Azevedo, C. R. F.; Sinatora, A. 2004. Failure analysis of a gas pipeline, Engineering Failure Analysis 11(3): 387-400. http://dx.doi.org/10.1016/j.engfailanal.2003.06.004

Balokhonov, R. R. 2010. Multiscale analysis of deformation and fracture mechanisms in composite materials, International Journal of Terraspace Science and Engineering 3(1): 13-37.

Baron, A. A. 2012. The generalized diagram of fracture toughness for pipeline steels, International Journal of Pressure Vessels and Piping 98: 26-29. http://dx.doi.org/10.1016/j.ijpvp.2012.06.003

Cramer, M.; Sevostianov, I. 2009. Effect of pore distribution on elastic stiffness and fracture toughness of porous materials, International Journal of Fracture 160(2): 189-196. http://dx.doi.org/10.1007/s10704-009-9416-6

Dominguez, D.; Sevostianov, I. 2011. Cross-property connection between work-hardening coefficient and electrical resistivity of stainless steel during plastic deformation, International Journal of Fracture 167(2): 281-287. http://dx.doi.org/10.1007/s10704-010-9556-8

Hood, J. E. 1974. Fracture of steel pipelines, International Journal of Pressure Vessels and Piping 2(3): 165-178. http://dx.doi.org/10.1016/0308-0161(74)90001-5

Ghajar, R.; Mirone, G.; Keshavarz, A. 2013. Ductile failure of X100 pipeline steel - experiments and fractography, Materials \& Design 43: 513-525.

http://dx.doi.org/10.1016/j.matdes.2012.07.032
Kachanov, M. 1999. Solids with cracks and non-spherical pores: proper parameters of defect density and effective elastic properties, International Journal of Fracture 97(14): 1-32. http://dx.doi.org/10.1023/A:1018345702490

Kadkhodapour, J.; Schmauder, S.; Raabe, D.; Ziaei-Rad, S.; Weber, U.; Calcagnotto, M. 2011. Experimental and numerical study on geometrically necessary dislocations and non-homogeneous mechanical properties of the ferrite phase in dual phase steels, Acta Materialia 59(11): 43874394. http://dx.doi.org/10.1016/j.actamat.2011.03.062

Kotrechko, S. O.; Krasowsky, A. Ya.; Meshkov, Yu. Ya.; Torop, V. M. 2004. Effect of long-term service on the tensile properties and capability of pipeline steel $17 \mathrm{GS}$ to resist cleavage fracture, International Journal of Pressure Vessels and Piping 81(4): 337-344. http://dx.doi.org/10.1016/j.ijpvp.2004.02.015

Kryzhanivs'kyi, E. I.; Nykyforchyn, H. M. 2011. Specific features of hydrogen-induced corrosion degradation of steels of gas and oil pipelines and oil storage reservoirs, Materials Science 47(2): 127-136.

http://dx.doi.org/10.1007/s11003-011-9390-9

Lebedev, A. A.; Chausov, N. G.; Bogdanovich, A. Z. 2002. Assessment of limiting damage in materials under static loading with the account of a stress state, Strength of $\mathrm{Ma}$ terials 34(2): 131-134. http://dx.doi.org/10.1023/A:1015354224871

Lebedev, A. A.; Chausov, N. G.; Boginich, I. O.; Nedoseka, S. A. 1996. Systematic evaluation of the damage to a material during plastic deformation, Strength of Materials 28(5): 347-352. http://dx.doi.org/10.1007/BF02330851

Liang, P.; Li, X.; Du, C.; Chen, X. 2009. Stress corrosion cracking of X80 pipeline steel in simulated alkaline soil solution, Materials \& Design 30(5): 1712-1717. http://dx.doi.org/10.1016/j.matdes.2008.07.012

Lublińska, K.; Tsyrulnyk, O.; Hredil, M.; Nykyforchyn, H.; Kurzydłowski, K. J. 2007. Stress corrosion cracking of the clad structural steels after its high temperature hydrogen degradation, Advances in Materials Science 7(1): 27-32.

Makarov, P. V. 2010. Self-organized criticality of deformation and prospects for fracture prediction, Physical Mesomechanics 13(5-6): 292-305. http://dx.doi.org/10.1016/j.physme.2010.11.010

Makarov, P. V. 2000. Localized deformation and fracture of polycrystals at mesolevel, Theoretical and Applied Fracture Mechanics 33(1): 23-30. http://dx.doi.org/10.1016/S0167-8442(99)00048-8

Maruschak, P.; Poberezhny, L.; Pyrig, T. 2013a. Fatigue and brittle fracture of carbon steel of gas and oil pipelines, Transport 28(3): 270-275. http://dx.doi.org/10.3846/16484142.2013.829782

Maruschak, P.; Baran, D.; Gliha, V. 2013b. A multiscale approach to deformation and fracture of heat-resistant steel under static and cyclic loading, Materials Science (Medžiagotyra) 19(1): 29-33.

http://dx.doi.org/10.5755/j01.ms.19.1.3821

Maruschak, P. O.; Konovalenko, I. V.; Bishchak, R. T. 2012. Effect of thermal fatigue cracks on brittle-ductile deformation and failure of CBCM roller surface layers, Metallurgist 56(1-2): 30-36. http://dx.doi.org/10.1007/s11015-012-9532-9

Mishnaevsky, L.; Weber, U.; Schmauder, S. 2004. Numerical analysis of the effect of microstructures of particlereinforced metallic materials on the crack growth and fracture resistance, International Journal of Fracture 125(1): 33-50.

http://dx.doi.org/10.1023/B:FRAC.0000021031.67717.9f 
Nykyforchyn, H.; Lunarska, E.; Tsyrulnyk, O.; Nikiforov, K.; Gabetta, G. 2009. Effect of the long-term service of the gas pipeline on the properties of the ferrite-pearlite steel, Materials and Corrosion 60(9): 716-725. http://dx.doi.org/10.1002/maco.200805158

Nykyforchyn, H.; Lunarska, E.; Tsyrulnyk, O. T.; Nikiforov, K.; Genarro, M. E.; Gabetta, G. 2010. Environmentally assisted "in-bulk" steel degradation of long term service gas trunkline, Engineering Failure Analysis 17(3): 624-632.

http://dx.doi.org/10.1016/j.engfailanal.2009.04.007

Panin, V. E.; Egorushkin, V. E. 2011. Deformable solid as a nonlinear hierarchically organized system, Physical Mesomechanics 14(5-6): 207-223.

http://dx.doi.org/10.1016/j.physme.2011.12.002
Teirlinck, D.; Zok, F.; Embury J. D.; Ashby M. F. 1988. Fracture mechanism maps in stress space, Acta Metallurgica 36(5): 1213-1228. http://dx.doi.org/10.1016/0001-6160(88)90274-X

Yasnii, P. V.; Marushchak, P. O.; Bishchak, R. T.; Panin, S. V. 2012. Deterioration of heat-resistant steel after prolonged operation, Russian Engineering Research 32(4): 364-367. http://dx.doi.org/10.3103/S1068798X12040296

Yasniy, P.; Maruschak, P.; Bishchak, R.; Hlado V.; Pylypenko, A. 2009. Damage and fracture of heat resistance steel under cyclic thermal loading, Theoretical and Applied Fracture Mechanics 52(1): 22-25. http://dx.doi.org/10.1016/j.tafmec.2009.06.005

Pavlo MARUSCHAK. Doctor, Professor, Department of Industrial Automation, Ternopil National Ivan Pul'uj Technical University, Ukraine. Research interests: transport engineering, pipeline transport, industrial transport, sea and air transport.

Iryna DANYLIUK. Post-graduate student, Department of Industrial Automation, Ternopil National Ivan Pul'uj Technical University, Ukraine. Research interests: transport engineering, pipeline transport, industrial transport, sea and air transport, industrial automation.

Olegas PRENTKOVSKIS. Doctor, Professor, Department of Transport Technological Equipment, Vilnius Gediminas Technical University, Lithuania. Research interests: vehicles dynamics, simulation of traffic accidents, traffic safety problems, transport infrastructure, numerical methods, pipeline transport.

Roman BISHCHAK. Doctor, Assistant professor, Department of Welding of Main Pipelines, Ivano-Frankivsk National Technical University of Oil and Gas, Ukraine. Research interests: fatigue, fracture mechanics, welding, oil pipelines, pipeline operation, protection, inspection and maintenance.

Andriy PYLYPENKO. Doctor, Assistant professor, Department of Strength of Materials, National University of Life and Environmental Sciences of Ukraine, Ukraine. Research interests: gas transportation systems, in-service defects analysis, fracture mechanics.

Andriy SOROCHAK. Lecturer, Department of Civil Engineering, Ternopil National Ivan Pul'uj Technical University, Ukraine. Research interests: structural and fractographic analysis, fracture mechanics, microscopy and microanalysis. 